\title{
Role of executive functions in the conversion from mild cognitive impairment to dementia
}

\begin{abstract}
Almudena Junquera Fernández. Departamento de Psicología Experimental, Procesos Cognitivos y Logopedia. Facultad de Psicología, Universidad Complutense de Madrid, España
\end{abstract}

Estefanía García Zamora. Departamento de Psicología Experimental, Procesos Cognitivos y Logopedia. Facultad de Psicología, Universidad Complutense de Madrid, España

Javier Olazarán Rodríguez. Hospital General Universitario Gregorio Marañón, Madrid, España

Mario A. Parra Rodríguez. School of Psychological Sciences and Health, University of Strathclyde, Glasgow, UK. Neuroprogressive and Dementia Network, NHS Scotland, UK. Universidad Autónoma del Caribe, Barranquilla, Colombia

Sara Fernández Guinea. Departamento de Psicología Experimental, Procesos Cognitivos y Logopedia. Facultad de Psicología, Universidad Complutense de Madrid, España

Running title: EEFF ability to predict Alzheimer's Disease

\section{Corresponding Author: Sara Fernández Guinea}

Email: sguinea@psi.ucm.es

Telephone number: (+34) 913943110

Fax: 913943189

Address: Carretera de Húmera s/n, Campus de Somosaguas, 28223 Pozuelo de Alarcón, Madrid. 


\section{Abstract}

Background: Recent researches pointed to executive dysfunction as a potential early predictor of the progression Mild Cognitive Impairment (MCI) - dementia in Alzheimer's clinical syndrome (ACS). Such cognitive impairments account for functional impairments in instrumental activities of daily living (IADL). Objective: The present study analyse the contributions of executive functions to predict MCI - dementia progression in ACS. Methods: We assessed 145 participants, 51 cognitively unimpaired and 94 MCI. The latter were divided using the traditional, memory-based MCI classification (single domain amnestic, multidomain amnestic and non-amnestic). Eight tests assessing executive functions were administered at baseline and at 1-year follow-up, together with cognitive screening tools and IADL measures. MCI patients were reclassified based on the outcomes from a K-mean cluster analysis which identified three groups. A simple lineal regression model was used to examine whether the classification based on executive functioning could more accurately predict progression to dementia a year later. Results: Clusters based on executive function deficits explained a significant proportion of the variance linked to MCI - dementia conversion, even after controlling for the severity of MCI at baseline $\left(F(1,68)=116.25, \mathrm{p}=0.000, \mathrm{R}^{2}=0.63\right)$. Classical memory-based MCI classification failed to predict such a conversion $(F(1,68)=5.09, \mathrm{p}=0.955$, $\mathrm{R}^{2}=0.07$ ). Switching, categories generation and planning were the executive functions that best distinguished between MCI converters and stable. Conclusion: MCI with a dysexecutive phenotype significantly predicts conversion to dementia in ACS a year later. Switching abilities and verbal fluency (categories) must be evaluated in MCI patients to assess risk of future dementia.

Keywords: activities of daily living, Alzheimer Disease, cognitive dysfunction, executive function, longitudinal studies. 


\section{Introduction}

Mild Cognitive Impairment (MCI) is understood as a risk state for dementia $[1,2,3,4,5]$. MCI patients could progress to dementia (from 4 to $15 \%$ in clinical setting ${ }^{[6]}$ and from 4 to as high as $17 \%$ in community-based studies ${ }^{[7]}$ ), could remain stable or could even revert to a normal cognition $[4,8,9,10,11,12]$. It is a current target to identify those who hold a high risk of progressing to dementia to provide interventions that can prevent or slow further cognitive decline.

Memory is the cognitive domain that has been more widely studied in the early stages of Alzheimer's clinical syndrome (ACS). Memory's decline follows a trajectory similar to that seen in general cognitive functioning ${ }^{[5,8]}$. In addition, memory decline could predict the transit from normal cognitive functioning to MCI and from MCI to dementia in $\operatorname{ACS}[13,14,15,16]$. However, memory is not the only cognitive function that decline early in Alzheimer's [5, 8, 17]. This has led to investigate whether the combined assessment of episodic memory and other cognitive domains, such as executive functioning, could increase sensitivity and reliability $[9,12,18,19,20]$. Such studies have focused on executive dysfunction as an early potential predictor of the progression to dementia stage in ACS due to their relation to pathological aging and dysfunctions in activities of daily living whether basic (ADL) ${ }^{[2,21,22]}$ or instrumental (IADL) ${ }^{[23]}$. Executive functions such as inhibition, planning or decision making, which are impaired in MCI, are known to preclude patients' independence in their IADL/ADL ${ }^{[5,10,13,24]}$.

Therefore, some researches have focused on executive dysfunction as a subtype of MCI - dysexecutive MCI. Using screening tests for ACS, Mez et al. ${ }^{[21]}$ noticed that a dysexecutive MCI subgroup declined faster than an amnestic group. They suggested that such groups follow different disease trajectories ${ }^{[5,20]}$. Kuzmickienè \& Kaubrys ${ }^{[17]}$ 
confirmed that executive disorders could have worse effects on ADL and quality of life of patients than memory disorders and explained that the main feature of dysexecutive function is cognitive slowing.

The evidence above supports the need of further longitudinal assessments to ascertain if impaired executive functions could be an early predictor of progression from MCI to dementia in the ACS. Supporting this notion is the subtype of MCI that presents with memory and other cognitive impairments (multidomain amnesic MCI - maMCI), being executive functions those more commonly affected ${ }^{[9,25]}$. Some studies pointed out that

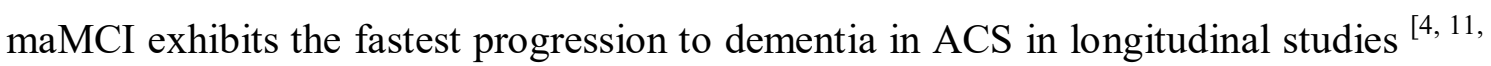
12]. Notwithstanding the evidence remains mixed with some studies showing that dysexecutive MCI holds a higher risk to progress to dementia in ACS ${ }^{[2]}$, while others concluded that amnestic and multidomain-amnestic MCI had a similar risk of conversion to that dementia ${ }^{[26]}$.

It is acknowledged that MCI is a heterogeneous condition ${ }^{[3,12,14]}$ which needs to be carefully considered when assessing risk of dementia in the ACS. Recent consensus papers try to address this by encouraging the use of biomarkers ${ }^{[27,28,29]}$. However, those papers acknowledge that while such methodologies become more widely available, better characterization of neuropsychological profiles will be necessary to enhance the reliability of clinical criteria ${ }^{[30]}$.

Taken together the evidence discussed above and recent calls for better forms of assessment, the present study focuses on dysexecutive MCI as a promising phenotype of MCI linked to dementia risk in the ACS. To this aim, we contrasted the risk of developing dementia in the ACS ${ }^{[29]}$ depending on whether MCI patients were grouped based on the classical memory-based deficits (amnesic MCI, multidomain amnesic MCI 
and non-amnesic MCI) or the dysexecutive profile. Such an approach, which explicitly compares the predictive value of the traditional MCI classification with that of other approaches aimed at enhancing cognitive phenotypes of risk among MCI patients, has not reported in the relevant literature to date. We hypothesized that the dysexecutive profile would predict MCI to dementia progression better than the traditional MCI classification. From this perspective, our study focuses on distilling the precise contribution of executive function impairments found in maMCI to dementia progression in the ACS.

\section{Methods}

\section{Participants}

A total of 148 participants took part in this research. Three of them were excluded since their cognitive decline was at a more advanced stage than MCI ${ }^{[29]}$, confirmed by a neurologist. 145 participants (108 females and 37 males) were included and divided in two groups, cognitively unimpaired $(\mathrm{n}=51)$ and MCI patients $(\mathrm{n}=94)^{[29]}$. They completed two extensive neuropsychological assessments one year apart. Participants were recruited from different hospitals and senior centres from Madrid. In accordance with the Declaration of Helsinki (1991), participants were fully informed about the aims of the study and they provided informed consent for longitudinal assessment prior to their enrolment. Participants did not report significant medical, neurological, vascular or psychiatric conditions, history of alcohol abuse or sensory impairment.

The cognitively unimpaired (CU) group was formed by elderly adults with no cognitive complaints and preserved neuropsychological and functional abilities as informed by the Mini-Mental State Examination (MMSE > $26^{[31,32]}$; obtained from Addenbrooke's 
Cognitive Examination Revised, ACE-R ${ }^{[33]}$ ) and Lawton \& Brody IADL (Lawton \& Brody $=8$ for women and Lawton $\&$ Brody $>5$ for men ${ }^{[34]}$.

Elderly adults entered the study as MCI patients if they have informant-corroborated subjective complaints of declining memory functioning, impaired performance on general cognitive scales (MMSE scores between 24 and $26^{[31,32,33]}$ ), Verbal Learning Test España-Complutense or TAVEC (TAVEC scores 1.5 SD below age norms ${ }^{[35]}$ ) and Rey Osterrieth Complex Figure test (test score 1.5 SD below age norms ${ }^{[36]}$ ); mildly impaired IADL (Lawton \& Brody $<8$ for women and Lawton \& Brody $<5$ for men ${ }^{[34]}$ ), and a Clinical Dementia Rating (CDR) between 0 and $0.5^{[37]}$. MCI patients did not differ from healthy controls on the Geriatric Depression Scale (GDS $<5^{[38]}$ ).

MCI patients were subsequently classified on the basis of the traditional criteria ${ }^{[1,39]}$ in: Single Domain Amnestic MCI (a-MCI) if participants have objective memory impairment (defined as a test score 1.5 SD below age norms on the TAVEC Immediate recall (Spanish adaptation of California Verbal Learning Test), TAVEC Delayed recall and Immediate recall of the Figure of Rey); Multidomain Amnestic MCI (ma-MCI) if participants have objective memory impairment (defined as a test score 1.5 SD below age norms on the TAVEC Delayed and Immediate recall and Immediate recall of the Figure of Rey) plus other cognitive domain deficits (language, executive functions, visuo-spatial ability, attention - measured as explains in assessment below); and Nonamnestic MCI (na-MCI) if participants have no objective memory impairment (defined by a test score equal or above 1.5 SD from age norms on the TAVEC Immediate and delayed recall and the Immediate recall of the Figure of Rey); and a test score below 1.5 SD from the norms on other cognitive domains such as language, executive functions or visuo-spatial ability. Tests assessing these domains were specified below. In addition, 
classification of MCI was contingent upon the lack of evidence of dementia as informed by a MMSE $<24$ and lack of IADL impairments which precluded independent living.

In the non-amnesic MCI sample we found that 2 patients presented with language deficits (2.13\% of MCI sample), 8 with executive dysfunction (8.51\%), 7 with executive dysfunction and language deficits (7.45\%) and 1 with executive dysfunction, language deficits, and visuoperceptual impairments (1.06\%). Moreover, 10 of the 18 non-amnestic MCI patients were of single domain and 8 were multiple domain nonamnestic MCI.

Diagnosis was confirmed by an external clinical auditor composed by neurologists who analysed blind data.

\section{Assessment}

148 participants were assessed at baseline in two sessions that took 90 minutes, and 108 of them were followed up $12( \pm 1)$ months after. Attrition was $27.03 \%$ and it was due to patients' mobility issues (Figure 1).

Our neuropsychological battery included screening test: MMSE (obtained from Addenbrooke's Cognitive Examination Revised, ACE-R ${ }^{[33]}$, functional and clinical scales: Lawton \& Brody ${ }^{[34]}$, ECOG Scale ${ }^{[40]}$, Blessed Scale ${ }^{[41]}$, CDR ${ }^{[37]}$ and The Neuropsychiatric Inventory - Questionnaire (NPI-Q) ${ }^{[42]}$.

The assessment also comprised tests that measure cognitive domains such as memory: Verbal Learning Test España-Complutense (TAVEC ${ }^{[35]}$ ), Rey Osterrieth Complex Figure test ${ }^{[36]}$; language: Boston Naming Test (short format) ${ }^{[43]}$; visuo-spatial ability: Rey Osterrieth Complex Figure test; attention: digits (WAIS-IV ${ }^{[44]}$ ) and Stroop Test ${ }^{[45]}$; and executive functions from WAIS-IV: Similarities, Arithmetic, Reverse Digits, 
and Letters and Numbers, Trail-Making Test $\left(\right.$ TMT $^{[46]}$ ); Stroop Test; Verbal Fluency phonemic and categories ${ }^{[47]}$; and Zoo Map included in Behavioural Assessment of Dysexecutive Syndrome (BADS ${ }^{[48]}$ ) where final profile score was taken into account. Executive function components were analysed: planning, categorization, verbal fluency, inhibition and switching ${ }^{[49,50]}$.

\section{Statistical Analysis}

Comparisons between groups for demographic characteristics, clinical questionnaires, clinical neuropsychological tests and executive function tests were performed using parametric $t$ test and cohen-d for calculating effect size. A multiple comparison using ANCOVA analysis was performed to compare MCI groups, using age as covariate. These comparisons between groups were followed up by Bonferroni corrected post-hoc tests.

K-Mean cluster analysis was carried out to identify clusters of MCI patients using executive function variables (TMT B-A, Verbal Fluency phonemic - FAS, Verbal Fluency Semantic - Categories (Animals, Fruits, Cookware and clothes), Stroop Test, Zoo Test, Similarities, Arithmetics, Reverse Digits and Letters and Numbers from WAIS). We decided to build three groups of dysexecutive MCI to follow the traditional MCI classification (aMCI, maMCI and naMCI). We were interested in exploring the mapping between the new executive function and the traditional memory classification. Four iterations were necessary to perform the analysis. A multiple comparison using ANCOVA analysis was then performed to compare clusters using age as covariate. These comparisons between groups were followed up by Bonferroni corrected post-hoc tests. Z-scores were obtained and groups and clusters analysis were performed in order 
to corroborate significant differences among MCI and control groups first, and among clusters and controls then.

In order to compare which classification better accounted for progression to dementia in the ACS, linear regression analysis was performed using conversion to dementia in ACS as the dependent variable and MCI groups or clusters as predictors. Then, stepwise regression analyses were performed using classical / dysexecutive MCI classification and MMSE as covariate to controls for the effect of baseline disease severity. An additional stepwise regression analysis was carried out to assess the potential influences of other neuropsychological impairments (i.e., language) to dysexecutive profiles in MCI patients. The rationale for such an analysis was that the neuropsychological tasks used in our assessment protocol also tax language functions. It is therefore relevant to disentangle the contribution of such cognitive domains to profiles of risk of dementia among MCI patients.

\section{Results}

\section{Classical MCI groups}

MCI groups showed significantly worse performance than CU at baseline and at oneyear follow-up on most clinical and neuropsychological measures (Table 1). Significant differences in $\mathrm{CU}$ and $\mathrm{MCI}$ were not found a year later, which means that groups remain stable over a year of follow up assessment (Table 2).

Among MCI participants, 26 were identified as a-MCI, 50 as ma-MCI and 18 as naMCI. There were no significant differences between groups in education $(F(3,149)=$ 
$2.55, \mathrm{p}=0.06$ ). As age was found to be significantly different between groups, it entered ANCOVA as a covariable. Ma-MCI group was the one with worse performance on most of the neuropsychological tests (Table 3 and Table 4). Moreover, on inspection of z-scores, maMCI was the group with more significant differences from $\mathrm{CU}$ both at baseline and at one year follow-up (Table 5). In addition, NPI-Q data revealed significant difference between MCI groups neither at baseline $(p=0.172)$ nor at 1 year follow-up assessment ( $\mathrm{p}=0.063)$.

\section{Groups from cluster analysis}

The analysis identified 3 clusters of MCI patients. As it is shown in Figure 2, Cluster 1 $(\mathrm{N}=56)$ has the most heterogeneous mixture of classical MCI groups, Cluster $2(\mathrm{~N}=28)$ includes mainly multidomain and non-amnestic MCI (memory is not the only cognitive domain impaired or it is not impaired, respectively) and Cluster $3(\mathrm{~N}=10)$ includes only multidomain amnestic MCI. The distance between cluster 1 and cluster 3 was the largest $(d=425.53)$, between cluster 1 and cluster 2 was the shortest $(d=192.91)$, and between clusters 2 and 3 was in the middle $(d=232.94)$, thus suggesting that cluster 3 was the most independent whereas cluster 1 and 2 shared characteristics.

Analysis of clinical phenotypes of patients falling within these clusters was carried out. As age was found to be significantly different between clusters, it entered ANCOVA as a covariable.

Significant differences were found when comparing the three clusters and these against the CU group (Table 6). As suggested by the cluster analysis, cluster 3 proved to be the most distinct, with the largest number of significant differences resulting from 
comparisons with cluster 1 , followed by comparisons with cluster 2 . These cluster also showed a large number of significant contrasts when compared to CU group (Table 7).

\section{Analysis of dementia conversion}

Our longitudinal data confirmed that only ma-MCI patients progressed to dementia in the ACS a year later (10/48 participants) when classical memory-based MCI classification was considered. Our cluster analysis identifying dysexecutive MCI revealed that progression to dementia in ACS was only observed in patients from cluster 3 (10/10 participants) which all happened to be in the ma-MCI category (Table 8).

These results suggest that progressing to dementia in ACS is more likely if in the maMCI category, and based on cluster analysis this progression is contingent upon impairments in the domain of executive function with $100 \%$ of patients from cluster 3 (purely ma-MCI) progressing to dementia a year later (Table 8).

When compared MCI converters versus MCI stable (Table 9) across the core executive functions, we found that TMT B-A and Verbal Fluency - Categories were those with the largest discrepancies. These were followed by the Zoo test, Phonemic Fluency (FAS), Letters and Number, and Similarities.

Moreover, when executive function components were analysed to find which of them was more accurate predicting conversion from MCI to dementia in ACS (table 10), simple and stepwise linear regression models showed that TMTB-A and Verbal Fluency

- Categories explained together $45 \%$ of variance associated to MCI-dementia progression in $\operatorname{ACS}\left(F(2,67)=27.49, \mathrm{p}=0.000, \mathrm{R}^{2}=0.45\right)$.

The simple linear regression model (Table 11) revealed that the classical classification of MCI as a predictor did not account for a significant proportion variance when 
considering progression to dementia in ACS as the dependent variable $(\mathrm{F}(1,68)=0.08$, $\left.\mathrm{p}=0.776, \mathrm{R}^{2}=0.00\right)$. However, the dysexecutive classification of MCI resulting from cluster analysis entering as a predictor and progression to dementia in ACS as the dependent variable did $\left(\mathrm{F}(1,68)=41.92, \mathrm{p}<.001, \mathrm{R}^{2}=0.38\right)$. A stepwise regression model covariating for disease severity using the MMSE and assessing the dysexecutive classification of $\mathrm{MCI}$ as a predictor and progression to dementia in ACS as the dependent variable yielded significant results after excluding the $\operatorname{MMSE}(F(1,68)=$ 116.25, $\mathrm{p}<.001, \mathrm{R}^{2}=0.63$ ). When the same model was run with the classical MCI classification only the MMSE accounted for a significant proportion of variance across MCI converters and non-converters with the classical MCI classification excluded $(F(1$, $\left.68)=5.09, \mathrm{p}=0.955, \mathrm{R}^{2}=0.07\right)$. This analysis was also run using ACE-R and CDR instead of MMSE and similar results were found.

The additional stepwise regression analysis (Table 12) ruled out the potential influences of language impairments to the dysexecutive MCI phenotype that best predicted risks of dementia conversion. The model that significantly accounted for conversion to dementia retained the dysexecutive subtypes classification and Category fluency as best predictors $\left(F(2,67)=62.93, \mathrm{p}<0.001, \mathrm{R}^{2}=0.64\right)$ and excluded the Boston Test and Phonemic Fluency. These results support the notion that the presence of dysexecutive impairments in the maMCI profile increases risk to dementia independently of language impairments.

\section{Discussion}

The present study was set out to investigate whether the classical MCI classification and one based on a dysexecutive profile could equally predict risk of developing dementia 
in the ACS. In line with our hypotheses, we focused on the amnestic MCI phenotype as this is the MCI subtype that has been linked to the highest risk of progression to dementia in the ACS. We found a rate of conversion to dementia of $10.64 \%$ in our MCI patients, which is rate consistent with previous studies ${ }^{[6,59]}$. Our results confirm that ma-MCI is the classical MCI group which is more likely to progress to dementia in the ACS a year later ${ }^{[4,11]}$, since there were neither single domain amnestic MCI nor nonamnestic MCI patients that progressed to dementia (Table 8). Therefore, ma-MCI was the MCI group with the highest rate of conversion to dementia in the ACS and executive functions was the cognitive domain that added most to the neuropsychological phenotype of this MCI group ${ }^{[9,25]}$. Therefore, we examined executive functions as a possible predictor of MCI to dementia progression in ACS. To this aim, we needed a MCI classification which was not solely based on memory impairments but would consider executive functions (dysexecutive MCI), as other researcher groups have previously done ${ }^{[2,5,21,22,23]}$. We found that dysexecutive MCI classification significantly predicted the probability of developing dementia in the ACS a year later. This result is consistent with those that previously pointed to executive functions as the cognitive domain more reliably linked to dementia in ACS in MCI patients $[9,10,19,20,23,51]$. In addition, traditional memory-based MCI classification did not significantly predict MCI to dementia progression in ACS. This finding is consistent with other studies that suggested that memory-based classifications may not provide the best framework to identify and predict dementia in in the symptomatic stages of the ACS ${ }^{[8,12]}$. Our results show that dysexecutive MCI classification is more accurate than memory-based classification to predict MCI to dementia conversion in ACS. Of note, we observed that the dysexecutive MCI classification predicted $63 \%$ of the variance of the conversion, even when controlling for severity of the disease at baseline. Thus, the 
predictive value of executive functions cannot be attributed to disease severity as it has been often claimed for ma-MCI ${ }^{[2,4,9,11]}$. Furthermore, as we did not find significant neuropsychiatric disturbances in our MCI groups, we feel confident to suggest that executive functions' deficits are a key feature of the MCI phenotype linked to risk to progression to dementia in the ACS.

Moreover, we showed that switching and categories verbal fluency are the executive function components that better predict MCI to dementia conversion in the ACS a year later (table 10). These findings are consistent with those from other authors ${ }^{[50-57]}$ who supported that category generation should be included in cognitive composites to predict cognitive decline. However, a failure in category verbal fluency may be indicative of language impairment ${ }^{[55]}$. Our results have shown that it is the executive component which is impaired in fluency tasks insofar as naming and phonemic fluency were excluded as predictors of MCI to dementia progression from a regression model (Table 12). This result reinforces the idea that executive functions play a key role in pathological aging and that they could be an early predictor of dementia in ACS. Our recommendation is that to better identify MCI profiles which hold predictive value for conversion to dementia in ACS, assessment of categories generation, switching and planning abilities must be carried out.

As MCI converters showed a phenotype that combined dysexecutive and amnestic features, corroborating the presence of the latter would remain an essential aim of the assessment. As was suggested by other authors ${ }^{[5,9,12,14,19,20]}$, a combination of memory and executive function tests enables researchers to detect severity of MCI and to predict if the person will suffer dementia related with ACS. Our findings further support this proposal and suggest that dysexecutive abilities contribute significantly to the risk profile of MCI patients. 
Since executive functioning is essential to maintain independence in daily living tasks ${ }^{[5}$, $10,13,23,24]$, we expected impairments when analysing IADL in clusters. As we have shown, cluster 3 is the one which is closer to dementia in ACS and with worse executive functions' performance. Moreover, cluster 3 showed the worst performance in IADL tests, such as Lawton \& Brody or CDR Sum of boxes (Table 6). These results taken together reinforce the idea that impairment in executive function's tasks is directly related with a loss of autonomy in IADL. It is worth noting that dysexecutive impairments impacted on IADL and that IADL impairments are a key criterion to ascertain conversion from MCI to dementia in ACS. However, in our sample such association was independent of the MCI severity, indicating that outcomes from cognitive screening tools assessing severity of cognitive decline may not suffice to detect risk profiles. A more detailed neuropsychological assessment of executive and memory functions will be necessary to identify who may more likely progress to the dementia stages regardless of the severity of their cognitive impairments.

Finally, some limitations of the current study are worth noting. The non-amnestic MCI sample was not large enough to enable an exhaustive analysis of each subtype based on the traditional classification. This sample size limitation also precluded the possibility of investigating phenotypes linked to non-AD or atypical $\mathrm{AD}$ variants. Furthermore, as our main objective was to identify predictors of risk of conversion to dementia seemingly of the Alzheimer's type, the amnestic subtype was more relevant to such an aim. Future research could adopt the phenotyping model proposed here to evaluate clinical trajectories of non-amnestic MCI groups. .

\section{Conclusions}


This study constributes novel evidence on the role of a dysexecutive MCI to predict risk of progression to dementia among MCI patients. We have demonstrated that such a classification holds higher accuracy to predict dementia a year later than the traditional MCI classification. Worse performance on executive function tasks in ma-MCI seems to indicate a higher risk of conversion to dementia in the ACS. Executive functions, specially switching and category generation, must be evaluated when looking for risk of dementia in MCI patients.

\section{Acknowledgments}

This work was supported by funding from Programa Operativo de Empleo Juvenil de la Consejería de Educación, Juventud y Deporte de la Comunidad de Madrid and Iniciativa de Empleo Juvenil (YEI) del Fondo Social Europeo. MAP work was supported by Alzheimer's Society through the grants AS-R42303 and AS-SF-14-008 awarded in collaboration with SFG.

\section{Conflict of interest}

The authors have no conflict of interest to report. 


\section{References}

1. Petersen RC (2004) Mild cognitive impairment as a diagnostic entity. Journal of Internal Medicine, 256(3), 183-194.

2. Aretouli E, Tsilidis KK, Brandt J (2013) Four-year outcome of mild cognitive impairment: The contribution of executive dysfunction. Neuropsychology, 27(1), 95-106. doi://dx.doi.org/10.1037/a0030481

3. Petersen RC, Caracciolo B, Brayne C, Gauthier S, Jelic V, Fratiglioni L (2014) Mild cognitive impairment: a concept in evolution. Journal of Internal Medicine, 275(3), 214-228.

4. Raamana PR, Wen W, Kochan Na, Brodaty H, Sachdev PS, Wang L, Beg MF (2014) The sub-classification of amnestic mild cognitive impairment using MRI-based cortical thickness measures. Frontiers in Neurology, 5(76), 1-10.

5. Blanco E, Ugarriza I, Elcoroaristizabal X, Galdos L, Molano A, Bereincua R, . .., Fernández-Martínez M (2016) Dysexecutive syndrome in amnesic mild cognitive impairment: A multicenter study. BMC Neurology, 16, 88. doi:10.1186/s12883-016-0607-2

6. Grandea G, Cucumo V, Cova I, Ghretti R, Maggiore L, Lacorte E, ..., Mariani C (2016) Reversible mild cognitive impairment: te role of comorbidities at baseline evaluation. Journal of Alzheimer's Disease, 51, 57-67.

7. Manley JJ, Tang MX, Schupf N, Stern Y, Vonsattel JP, Mayeux R (2008) Frecuency and course of mild cognitive impairment in a multi-ethnic community. Annals of Neurology, 63, 494-506.

8. Johnson JK, Gross AL, Pa J, McLaren DG, Park LQ, Manly JJ (2012) Longitudinal change in neuropsychological performance using latent growth models: A study of mild cognitive impairment. Brain Imaging and Behaviour, 6(4), 540-550. doi:10.1007/s11682-012-9161-8

9. Belleville S, Gauthier S, Lepage É, Kergoat M, Gilbert B (2014) Predicting decline in mild cognitive impairment: A prospective cognitive study. Neuropsychology, 28(4), 643-652. doi://dx.doi.org/10.1037/neu0000063 
10. Hazlett KE, Figueroa CM, Nielson KA (2015) Executive functioning and risk for Alzheimer's disease in the cognitively intact: Family history predicts wisconsin card sorting test performance. Neuropsychology, 29(4), 582-591. doi:http://0dx.doi.org.cisne.sim.ucm.es/10.1037/neu0000181.

11. Toledo JB, Bjerke M, Chen K, Rozycki M, Jack CR Jr., Weiner MW, . . Trojanowski JQ (2015) Memory, executive, and multidomain subtle cognitive impairment: Clinical and biomarker findings. Neurology, 85(2), 144-153. doi:http://0dx.doi.org.cisne.sim.ucm.es/10.1212/WNL.0000000000001738.

12. Wilhalme H, Goukasian N, De Leon F, He A, Hwang KS., Woo E, . . Apostolova LG (2017) A comparison of theoretical and statistically derived indices for predicting cognitive decline. Alzheimer's \& Dementia (Amsterdam, Netherlands), 6, 171-181. doi:10.1016/j.dadm.2016.10.002.

13. Dickerson BC, Wolk DA (2011) Dysexecutive versus amnesic phenotypes of very mild alzheimer's disease are associated with distinct clinical, genetic and cortical thinning characteristics. Journal of Neurology, Neurosurgery, and Psychiatry, 82(1), 45-51. doi:10.1136/jnnp.2009.199505

14. Summers MJ, Saunders NLJ (2012) Neuropsychological measures predict decline to alzheimer's dementia from mild cognitive impairment. Neuropsychology, 26(4), 498-508. doi://dx.doi.org/10.1037/a0028576

15. Harrington MG, Chiang J, Pogoda JM, Gomez M, Thomas K, Marion SD, . . Fonteh AN (2013) Executive function changes before memory in preclinical alzheimer's pathology: A prospective, cross-sectional, case control study. PloS One, 8(11), e79378. doi:10.1371/journal.pone.0079378

16. Bradfield N, Ellis K, Savage G, Maruff P, Burnham S, ..., Ames D (2018) Baseline amnestic severity predicts progression from amnestic mild cognitive impairment to Alzheimer Disease dementia at 3 years. Alzheimer Disease \& Associated Disorders, 32(3), 190-196.

17. Kuzmickiené J, Kaubrys G (2016) Specific features of executive dysfunction in alzheimertype mild dementia based on computerized cambridge neuropsychological test automated 
battery (CANTAB) test results. Medical Science Monitor: International Medical Journal of Experimental and Clinical Research, 22, 3605-3613.

18. Saunders NLJ, Summers MJ (2011) Longitudinal deficits to attention, executive, and working memory in subtypes of mild cognitive impairment. Neuropsychology, 25(2), 237248. doi://dx.doi.org/10.1037/a0021134

19. Clark LR, Schiehser DM, Weissberger GH, Salmon DP, Delis DC, Bondi MW (2012) Specific measures of executive function predict cognitive decline in older adults. Journal of the International Neuropsychological Society: JINS, 18(1), 118-127. doi:10.1017/S1355617711001524

20. Kirova A, Bays RB, Lagalwar S (2015) Working memory and executive function decline across normal aging, mild cognitive impairment, and alzheimer's disease. BioMed Research International, 2015, 748212. doi:10.1155/2015/748212

21. Mez J, Cosentino S, Brickman AM, Huey ED, Manly JJ, Mayeux R (2013) Faster cognitive and functional decline in dysexecutive versus amnestic alzheimer's subgroups: A longitudinal analysis of the national alzheimer's coordinating center (NACC) database. PloS One, 8(6), e65246. doi:10.1371/journal.pone.0065246.

22. Reinvang I, Grambaite R, Espeseth T. (2012). Executive dysfunction in MCI: Subtype or Early Symptom. International Journal of Alzheimers Disease.

23. Marshall GA, Rentz DM, Frey MT, Locascio JJ, Johnson KA, Sperling RA (2011) Executive function and instrumental activities of daily living in mild cognitive impairment and alzheimer's disease. Alzheimer's \& Dementia: The Journal of the Alzheimer's Association, 7(3), 300-308. doi:10.1016/j.jalz.2010.04.005

24. Snyder HR, Miyake A, Hankin BL. (2015). Advancing understanding of executive function impairments and psycopathology: bridging the gap between clinical and cognitive approaches. Frontiers in Psycology, 6(328), 1-24.

25. Cespón J, Galdo-Álvarez S, Díaz F (2015) Inhibition deficit in the spatial tendency of the response in multiple-domain amnestic mild cognitive impairment. An event-related potential study. Frontiers in Aging Neuroscience, 7(68). 
26. Oltra-Cucarella J, Ferrer-Cascales R, Alegret M, Gasparini R, Díaz-Oritz L, .., SánchezSanSegundo M (2018) Risk of progression to Alzheimer's disease for different neuropsychological mild cognitive impairment subtypes: A hierarchical meta-analysis of longitudinal studies. American Psychological Association, 33(7), 1007-1021.

27. Dubois B, Hampel H, Feldman HH, Scheltens P, Aisen P, Andrieu S, . . Jack CR Jr. (2016) Preclinical Alzheimer's disease: Definition, natural history, and diagnostic criteria. Alzheimers. Dement, 12(3), 292-323. doi:S1552-5260(16)00050-9 [pii];10.1016/j.jalz.2016.02.002 [doi]

28. Jack CR, Bennett DA, Blennow K, Carrillo MC, Feldman HH, Frisoni GB, . . . Dubois B (2016) A/T/N: An unbiased descriptive classification scheme for Alzheimer disease biomarkers. Neurology, 87(5), 539-547. doi:10.1212/WNL.0000000000002923

29. Jack CR Jr., Bennett DA, Blennow K, Carrillo MC, Dunn B, Haeberlein SB, . . Sperling R (2018) NIA-AA Research Framework: Toward a biological definition of Alzheimer's disease. Alzheimer's \& Dementia, 14(4), 535.

30. Parra MA, Butler S, McGeown WJ, Brown LA, Robertson DJ (2019) Globalising strategies to meet global challenges: the case of ageing and dementia. Journal of Global Health, (in press).

31. Hoops S, Nazem S, Siderowf AD, Duda JE, Xie SX, Stern MB, Weintraub D (2009) Validity of the MoCA and MMSE in the detection of MCI and dementia in Parkinson disease. Neurology, 73(21), 1738-1745.

32. Stephan BCM, Minett T, Pagett E, Siervo M, Brayne C, McKeith IG (2013) Diagnosing Mild Cognitive Impairment (MCI) in clinical trials: a systematic review. BMJ Open, 3.

33. Mioshi E, Dawson K, Mitchell J, Arnold R, Hodges JR (2006) The Addenbrooke's Cognitive Examination Revised (ACE-R): a brief cognitive test battery for dementia screening. International Journal of Geriatric Psychiatry, 21(11), 1078-1085.

34. Lawton M, Brody E (1969) Assessment of older people: self-maintaining and instrumental activities of daily living. The Gerontolist, 9(3), 179-186. 
35. Benedet MJ, Alejandre MA (1998) Test de Aprendizaje Verbal España-Complutense (TAVEC). Publicaciones de Psicología Aplicada, 261, Madrid.

36. Osterrieth PA (1944) "Filetest de copie d'une figure complex: Contribution a l'etude de la perception et de la memoire [The test of copying a complex figure: A contribution to the study of perception and memory]". Archives de Psychologie. 30: 286-356.

37. Hughes CP, Berg L, Danziger WL, Coben LA, Martin RL (1982) A new clinical scale for the staging of dementia. The British Journal of Psychiatry, 140, 566-572.

38. Yesevage JA, Brink TL, Rose TL, Lum O, Huang V, Adey M, Leirer VO (1982) Development and validation of a geriatric depression screening scale: a preliminary report. Journal of Psychiatric Research, 17(1), 37-49.

39. Winblad B, Palmer K, Kivipelto M, Jelic V, Fratiglioni L, Wahlund LO, ..., Petersen RC (2004) Mild cognitive impairment - beyond controversies, towards a consensus: report of the International Working Group on Mild Cognitive Impairment. Journal of Internal Medicine, 256(3), 240-246.

40. Farias S, Mungas D, Harvey D, Simmons A, Reed B, Decarli C (2011) The measurement of everyday cognition: development and validation of a short form of the Everyday Cognition scales. Alzheimers \& Dementia, 7(6), 593-601. Doi:10.1016/j.jalz.2011.02.007

41. Blessed G, Tomlinson BE, Roth M (1968) The association between quantitative measures of dementia and of senile change in the cerebral grey matter grey matter of elderly subjects. The British Journal of Psychiatry, 114(512), 797-811.

42. Cummings JL, Mega M, Gray K, RosenbergThomson S, Carusi DA, Gambein J. (1994). The Neuropsychiatric Inventory: comprehensive assessment of psychopathology in dementia. Neurology, 44, 2308-14.

43. Goodglass H, Kaplan E, Barresi B (2001) The assessment of aphasia and related disorders ( $3^{\text {rd }}$ ed.). Austin, TX: Pro-ED.

44. Wechsler D (2012) WAIS-IV. Escala de inteligencia de Wechsler para adultos-IV. Manual técnico y de interpretación. Madrid: NCS Pearson, Inc. Edición original, 2008. 
45. Stroop JR (1935) Studies o interference in serial verbal reactions. Journal of Experimental Psychology, 18, 643-662.

46. Reitan RM, Wolfson D (1993) The Halstead-Reitan Neuropsychological Test Battery: Theory and clinical interpretation $\left(2^{\text {nd }}\right.$ ed.). Tucson: Neuropsychology Press.

47. Sumerall SW, Timmons PL, James AL, Ewing MJ, Oehlert ME (1997) Expanded norms for the Controlled Oral Word Association Test. Journal of Clinical Psychology, 53(5), 517-521.

48. Wilson BA, Alderman N, Burgess PW, Emslie H, Evans JJ. The behavioural assessment of the dysexecutive syndrome. Thames Valley Company; Bury St Edmunds: 1996.

49. Lezak MD (1982) The problem of assessing executive functions. International Journal of Psychology, 17, 281-297.

50. Goldberg E (2009) El cerebro ejecutivo, lóbulos frontales y mente civilizada. Barcelona: Crítica

51. Papp KV, Rentz DM, Orlovsky I, Sperling RA, Mormino EC (2017) Optimizing the preclinical Alzheimer's cognitive composite with semantic processing: The PACC5. Alzheimer's \& Dementia, 1-10.

52. Peter J, Kaiser J, Landerer V, Köstering L, Kaller CP, Heimbach B, ..., Klöppel S. (2016). Category and design fluency in mild cognitive impairment: Performance, strategy use, and neural correlates. Neuropsychologia, 93, 21-29.

53. Giacominelli C, Bertolucci PH \& Ferreira FP. (2017). Verbal fluency fruits as a predictor of Alzheimer's disease progression in Brazilian Portuguese speakers. Journal of Alzheimer's Disease \& Parkinsoninsm, 7(6).

54. Mirandez RM, Aprahamian I, Talib LL, Forlenza OV \& Radanovic M. (2017). Multiple category verbal fluency in mild cognitive impairment and correlation with CSF biomarkers for Alzheimer's disease. International Psychogeriatrics, 26(6), 949-958.

55. Alegret M, Peretó M, Pérez A, Valero S, Espinosa A, Ortega E, ..., Boada M. (2018). The role of verb fluency in the detection of early cognitive impairment in Alzheimer's disease. Journal of Alzheimer's Disease, 62, 611-619. 
56. García-Herranz S, Díaz-Mardomingo MC, Venero C \& Peraita H. (2019). Accuracy of verbal fluency tests in the discrimination of mild cognitive impairment and probable Alzheimer's disease in older Spanish monolingual individuals. Aging, Neuropsychology, and Cognition, DOI: 10.1080/13825585.2019.1698710

57. Quaranta D, Piccininni C, Caprara A, Malandrino A, Gainotti G \& Marra C. (2019). Semantic relations in a Categorical Verbal Fluency Test: an exploratory investigation in mild cognitive impairment. Frontiers in Psychology.

58. Putcha D, Dickerson BC, Brickhouse M, Johnson KA, Sperling R \& Papp KV. (2020). Word retrieval across the biomarker-confirmed Alzheimer's disease syndromic spectrum. Neuropsychologia, 140.

59. Manly JJ, Tang M, Schupf N, Stern Y, Vonsattel JP, Mayeus R. (2008). Frecuency and course of mild cognitive impairment in a multi-ethnic community. Annals of Neurology, 63(4), 494-506. 


\section{Tables}

Table 1: Baseline and 1 year follow-up clinical and socio-demographic characteristics in CU and MCI group

\begin{tabular}{|c|c|c|c|c|c|c|c|c|c|c|}
\hline & \multicolumn{5}{|c|}{ Baseline } & \multicolumn{5}{|c|}{1 year follow-up } \\
\hline & $\begin{array}{c}\mathbf{C U} \\
\mathbf{N}=\mathbf{5 1} \\
\mathbf{M}(\mathbf{S D})\end{array}$ & $\begin{array}{c}\text { MCI } \\
\mathbf{N}=94 \\
\text { M (SD) }\end{array}$ & $\mathbf{t}$ & Sig. & $\begin{array}{l}\text { Effect size } \\
\text { (cohen-d) }\end{array}$ & $\begin{array}{c}\mathbf{C U} \\
\mathbf{N}=\mathbf{3 6} \\
\mathbf{M}(\mathbf{S D})\end{array}$ & $\begin{array}{c}\text { MCI } \\
\mathbf{N}=\mathbf{7 2} \\
\mathbf{M} \text { (SD) }\end{array}$ & $\mathbf{t}$ & Sig. & $\begin{array}{l}\text { Effect size } \\
\text { (cohen-d) }\end{array}$ \\
\hline Age & $71.20(4.50)$ & $74.76(6.00)$ & -4.03 & $* * *$ & -0.67 & $71.29(4.21)$ & $76.07(6.38)$ & -4.57 & $* * *$ & -0.88 \\
\hline Education & 10.14 (4.97) & $8.66(4.72)$ & 1.77 & & 0.31 & $10.15(4.57)$ & $8.24(4.04)$ & 2.15 & $*$ & 0.44 \\
\hline GDS & $1.86(2.55)$ & $2.12(2.03)$ & -0.66 & & -0.11 & $1.44(1.64)$ & $2.15(2.21)$ & -1.65 & & -0.37 \\
\hline NPI-Q & $0.61(1.15)$ & $1.19(1.76)$ & -2.31 & $*$ & -0.39 & $1.60(2.05)$ & $1.66(1.77)$ & -0.15 & & -0.03 \\
\hline $\begin{array}{l}\text { Lawton \& } \\
\text { Brody }\end{array}$ & $7.91(0.59)$ & $7.59(0.89)$ & 2.60 & * & 0.42 & $8.00(0.00)$ & $7.16(1.47)$ & 4.79 & $* * *$ & 0.81 \\
\hline CDR total & $0.22(0.27)$ & $0.39(0.22)$ & -3.65 & $* * *$ & -0.69 & $0.09(0.19)$ & $0.41(0.30)$ & -6.68 & $* * *$ & -1.27 \\
\hline $\begin{array}{l}\text { CDR Sum } \\
\text { of boxes }\end{array}$ & $6.72(1.28)$ & $8.78(2.60)$ & -6.08 & $* * *$ & -1.01 & $6.52(1.03)$ & $9.50(3.52)$ & -6.33 & $* * *$ & -1.15 \\
\hline MMSE & 28.94 (1.36) & $27.14(2.67)$ & 5.38 & $* * *$ & 0.85 & $28.74(1.38)$ & $26.34(3.08)$ & 5.50 & $* * *$ & 1.01 \\
\hline $\begin{array}{l}\text { TAVEC } \\
\text { STM }\end{array}$ & $10.75(2.35)$ & $6.12(3.74)$ & 9.02 & $* * *$ & 1.48 & $10.49(3.82)$ & 5.97 (4.29) & 5.27 & $* * *$ & 1.11 \\
\hline $\begin{array}{l}\text { TAVEC } \\
\text { LTM }\end{array}$ & 11.77 (2.02) & $6.46(3.50)$ & 11.44 & $* * *$ & 1.86 & $11.17(3.51)$ & $6.50(4.50)$ & 5.83 & $* * *$ & 1.16 \\
\hline Rey STM & $17.35(6.05)$ & $11.21(7.38)$ & 5.26 & $* * *$ & 0.91 & $18.09(7.80)$ & $12.19(7.45)$ & 3.77 & $* * *$ & 0.77 \\
\hline
\end{tabular}

${ }^{*} \mathrm{p}<.05,{ }^{* *} \mathrm{p}<.005 * * * \mathrm{p}<.001$. STM is used to express Short Term Memory. LTM expresses Long Term Memory 
Table 2: Baseline and 1 year follow-up Z-scores comparation in clinical and sociodemographic characteristics in CU and MCI group

\begin{tabular}{|l|r|r|}
\hline \multirow{1}{*}{} & \multicolumn{2}{|c|}{$\begin{array}{c}\text { Baseline vs 1 year follow-up } \\
\text { CU Z-scores }\end{array}$} \\
& \multicolumn{2}{|c|}{ Baseline vs 1 year follow-up } \\
MCI Z-scores
\end{tabular}

${ }^{*} \mathrm{p}<.05, \quad * * \mathrm{p}<.005 * * * \mathrm{p}<.001$. STM is used to express Short Term Memory. LTM expresses Long Term Memory 
Table 3: Baseline clinical and socio-demographic characteristics of MCI sub-groups based on the classical classification

\begin{tabular}{|c|c|c|c|c|c|c|c|}
\hline & \multicolumn{7}{|c|}{ Baseline } \\
\hline & $\begin{array}{c}\mathbf{C U} \\
\mathbf{N}=\mathbf{5 1} \\
\mathbf{M}(\mathbf{S D})\end{array}$ & $\begin{array}{l}\text { aMCI } \\
N=26 \\
M \text { (SD) }\end{array}$ & $\begin{array}{c}\operatorname{maMCI} \\
\mathbf{N}=\mathbf{5 0} \\
\mathbf{M}(\mathrm{SD})\end{array}$ & $\begin{array}{l}\text { naMCI } \\
N=18 \\
M(\text { SD) }\end{array}$ & $\begin{array}{l}\text { F (3, } \\
145)\end{array}$ & Sig. & $\begin{array}{c}\text { Partial } \\
\text { ETA2 } \\
\end{array}$ \\
\hline Age & $71.20(4.50)$ & $74.73(4.53)$ & $75.61(6.46)$ & $72.24(6.14)$ & 6.29 & $* * * 1-2,1-3$ & 0.12 \\
\hline Education & $10.14(4.97)$ & $10.04(4.08)$ & $8.61(4.87)$ & $6.71(4.71)$ & 2.75 & $*$ & 0.05 \\
\hline GDS & $1.86(2.55)$ & $2.19(2.53)$ & $2.02(1.72)$ & $2.29(2.14)$ & 0.22 & & 0.01 \\
\hline NPI-Q & $0.61(1.15)$ & $1.27(2.13)$ & $1.28(1.63)$ & $0.82(1.55)$ & 1.69 & & 0.04 \\
\hline $\begin{array}{l}\text { Lawton \& } \\
\text { Brody }\end{array}$ & $7.91(0.59)$ & $7.58(0.99)$ & $7.49(0.95)$ & $7.88(0.33)$ & 2.77 & * & 0.04 \\
\hline CDR & $0.22(0.27)$ & $0.35(0.24)$ & $0.43(0.20)$ & $0.34(0.24)$ & 6.23 & $* * 1-3$ & 0.09 \\
\hline CDR boxes & $6.72(1.28)$ & $7.68(2.43)$ & $9.67(2.60)$ & $7.81(1.91)$ & 15.07 & $* * * 1-3,2-3,3-4$ & 0.20 \\
\hline MMSE & $28.94(1.36)$ & $28.54(1.27)$ & $26.20(2.99)$ & $27.77(2.45)$ & 15.27 & $* * * 1-3,2-3,3-4$ & 0.24 \\
\hline $\begin{array}{l}\text { TAVEC } \\
\text { STM }\end{array}$ & $10.75(2.35)$ & $6.46(3.09)$ & $4.63(3.53)$ & $10.06(1.98)$ & 41.34 & $* * * 1-2,1-3,2-4,3-4$ & 0.42 \\
\hline $\begin{array}{l}\text { TAVEC } \\
\text { LTM }\end{array}$ & $11.77(2.02)$ & $6.46(2.25)$ & $4.92(3.15)$ & $11.06(1.52)$ & 74.40 & $* * * 1-2,1-3,2-4,3-4$ & 0.58 \\
\hline Rey Copy & 33.49 (3.17) & $32.08(3.33)$ & $28.56(8.21)$ & $30.59(5.98)$ & 6.12 & $* * 1-3$ & 0.13 \\
\hline Rey STM & $17.35(6.05)$ & $11.73(6.51)$ & $9.36(7.28)$ & $15.97(7.05)$ & 12.89 & $* * * 1-2,1-3,3-4$ & 0.19 \\
\hline Rey LTM & $17.52(6.33)$ & $10.62(6.86)$ & $9.12(6.74)$ & $15.29(7.21)$ & 14.47 & $* * * 1-2,1-3,3-4$ & 0.21 \\
\hline Boston & $11.11(2.12)$ & $10.85(2.17)$ & $9.20(2.74)$ & $9.59(2.60)$ & 6.01 & $* * 1-3,2-3$ & 0.09 \\
\hline TMTBA & $88.96(62.90)$ & $87.54(45.24)$ & $239.06(159.55)$ & $182.00(112.82)$ & 18.38 & $* * * 1-3,1-4,2-3,2-4$ & 0.25 \\
\hline $\begin{array}{l}\text { FAS } \\
\text { Phonetics }\end{array}$ & $11.76(3.20)$ & $11.51(3.58)$ & $9.24(4.01)$ & $8.05(2.43)$ & 7.54 & $* * * 1-3,1-4,2-3,2-4$ & 0.13 \\
\hline $\begin{array}{l}\text { FAS } \\
\text { Categories }\end{array}$ & $15.16(2.63)$ & $14.38(2.29)$ & $11.59(2.81)$ & $13.63(2.34)$ & 16.35 & $* * * 1-3,2-3,3-4$ & 0.23 \\
\hline Stroop & $52.75(6.46)$ & $50.42(8.85)$ & $50.18(12.41)$ & $44.33(22.06)$ & 2.02 & & 0.04 \\
\hline Zoo & $1.93(1.14)$ & $1.50(1.42)$ & $0.25(1.21)$ & $0.94(1.44)$ & 15.19 & $* * * 1-3,1-4,2-3$ & 0.23 \\
\hline Similarities & $17.02(4.69)$ & $14.42(5.29)$ & $14.10(4.55)$ & $12.71(3.87)$ & 5.01 & $* * 1-3,1-4$ & 0.08 \\
\hline $\begin{array}{l}\text { Reverse } \\
\text { Digits }\end{array}$ & $5.27(1.59)$ & $5.38(2.00)$ & $4.41(1.40)$ & $4.18(1.70)$ & 4.14 & $*$ & 0.08 \\
\hline Arithmetics & $10.44(3.73)$ & $9.73(2.74)$ & $8.41(3.38)$ & $8.29(3.20)$ & 3.56 & $*^{1-3}$ & 0.09 \\
\hline $\begin{array}{l}\text { Letters \& } \\
\text { Numbers }\end{array}$ & $8.20(2.40)$ & $6.73(2.41)$ & $5.82(3.23)$ & $5.12(2.91)$ & 7.89 & $* * * 1-3,1-4$ & 0.12 \\
\hline
\end{tabular}

$* \mathrm{p}<.05, * * \mathrm{p}<.005, * * * \mathrm{p}<.001$. For Bonferroni analysis: $1=\mathrm{CU}, 2=\mathrm{aMCI}, 3=$ maMCI, $4=$ naMCI. STM

$=$ Short Term Memory, $\mathrm{LTM}=$ Long Term Memory 
Table 4: 1 year follow-up clinical and socio-demographic characteristics of MCI subgroups based on the classical classification

\begin{tabular}{|c|c|c|c|c|c|c|c|}
\hline & \multicolumn{7}{|c|}{1 year follow-up } \\
\hline & $\begin{array}{c}\mathrm{CU} \\
\mathbf{M}(\mathbf{S D})\end{array}$ & $\begin{array}{c}\mathbf{a M C I} \\
\mathbf{M}(\mathrm{SD})\end{array}$ & $\begin{array}{l}\text { maMCI } \\
M(S D)\end{array}$ & $\begin{array}{l}\text { naMCI } \\
\text { M (SD) }\end{array}$ & $\begin{array}{l}\text { F (3, } \\
104)\end{array}$ & Sig. & $\begin{array}{c}\text { Partial } \\
\text { ETA2 }\end{array}$ \\
\hline Age & $71.29(4.20)$ & $75.28(4.76)$ & $77.39(6.74)$ & $73.31(6.60)$ & 7.41 & $* * * 1-3$ & 0.18 \\
\hline Education & $10.15(4.57)$ & $9.72(3.86)$ & $7.92(4.33)$ & $7.08(2.96)$ & 2.71 & $*$ & 0.06 \\
\hline GDS & $1.44(1.64)$ & $1.89(2.35)$ & $2.27(2.26)$ & $2.15(1.99)$ & 1.03 & & 0.01 \\
\hline NPI-Q & $1.83(2.39)$ & $1.81(2.04)$ & $1.82(1.67)$ & $1.23(1.15)$ & 0.64 & & 0.03 \\
\hline $\begin{array}{l}\text { Lawton \& } \\
\text { Brody }\end{array}$ & $8.00(0.00)$ & $7.00(1.68)$ & $6.95(1.56)$ & $7.93(0.27)$ & 6.55 & $* * * 1-2,1-3$ & 0.10 \\
\hline CDR & $0.09(0.19)$ & $0.33(0.30)$ & $0.46(0.29)$ & $0.36(0.31)$ & 12.49 & $* * * 1-2,1-3,1-4$ & 0.23 \\
\hline CDR boxes & $6.52(1.03)$ & $8.67(3.52)$ & $10.16(3.59)$ & $8.54(3.13)$ & 8.79 & $* * * 1-3$ & 0.16 \\
\hline MMSE & $28.74(1.38)$ & $27.78(1.96)$ & $25.50(3.30)$ & $26.79(3.04)$ & 10.36 & $* * * 1-3,2-3$ & 0.19 \\
\hline TAVEC STM & $10.49(3.82)$ & $6.78(3.72)$ & $4.13(3.92)$ & $9.93(2.84)$ & 20.01 & $* * * 1-2,1-3,3-4$ & 0.33 \\
\hline TAVEC LTM & $11.17(3.51)$ & $6.50(4.00)$ & $4.82(4.11)$ & $11.07(2.76)$ & 21.62 & $* * * 1-2,1-3,2-4,3-4$ & 0.33 \\
\hline Rey Copy & $33.43(3.03)$ & $31.58(3.75)$ & $27.34(9.25)$ & $30.64(4.81)$ & 5.87 & $* * 1-3$ & 0.12 \\
\hline Rey STM & $18.09(7.80)$ & $14.61(5.15)$ & $9.07(7.14)$ & $17.54(6.87)$ & 11.33 & $* * * 1-3,2-3,3-4$ & 0.25 \\
\hline Rey LTM & $18.30(7.19)$ & $14.58(4.15)$ & $9.01(6.29)$ & $16.21(6.53)$ & 13.79 & $* * * 1-3,2-3,3-4$ & 0.27 \\
\hline Boston & $11.34(2.41)$ & $11.11(1.81)$ & $8.92(2.84)$ & $10.43(2.31)$ & 6.63 & $* * * 1-3,2-3$ & 0.12 \\
\hline ТМТВА & $81.14(59.47)$ & 99.61 (114.09) & $\begin{array}{c}198.84 \\
(158.47)\end{array}$ & $\begin{array}{l}177.79 \\
(77.80)\end{array}$ & 7.54 & $* * * 1-3,2-3$ & 0.15 \\
\hline FAS Phonetics & $12.29(3.66)$ & $11.71(3.67)$ & $8.71(4.11)$ & $8.28(3.26)$ & 7.62 & $* * * 1-3,1-4,2-3$ & 0.15 \\
\hline $\begin{array}{l}\text { FAS } \\
\text { Categories }\end{array}$ & $15.69(2.62)$ & $14.37(1.92)$ & $11.16(3.43)$ & $14.04(2.94)$ & 15.61 & $* * * 1-3,2-3,3-4$ & 0.22 \\
\hline Stroop & $52.43(11.53)$ & $49.44(14.98)$ & $49.14(11.40)$ & $48.50(24.90)$ & 0.43 & & 0.01 \\
\hline Zoo & $1.14(1.12)$ & $0.67(1.33)$ & $0.22(1.36)$ & $1.14(1.88)$ & 3.29 & $*^{1-3}$ & 0.09 \\
\hline Similarities & $18.71(5.13)$ & $15.94(3.93)$ & $13.03(4.74)$ & $14.64(4.70)$ & 8.96 & $* * * 1-3,1-4$ & 0.16 \\
\hline Reverse Digits & $5.43(1.46)$ & $5.06(1.66)$ & $4.16(1.82)$ & 4.07 (1.64) & 4.55 & $*^{1-3}$ & 0.10 \\
\hline Arithmetics & $8.71(3.11)$ & $9.50(4.13)$ & $7.76(3.09)$ & $6.64(2.53)$ & 2.58 & & 0.08 \\
\hline $\begin{array}{l}\text { Letters \& } \\
\text { Numbers }\end{array}$ & $8.06(2.33)$ & $7.56(2.92)$ & $5.00(3.09)$ & $5.00(2.83)$ & 9.49 & $* * * 1-3,1-4,2-3$ & 0.17 \\
\hline
\end{tabular}

${ }^{*} \mathrm{p}<.05,{ }^{*} \mathrm{p}<, 005,{ }^{*} * \mathrm{p}<.001$. For Bonferroni analysis: $1=\mathrm{CU}, 2=\mathrm{aMCI}, 3=\operatorname{maMCI}, 4=$ naMCI. STM $=$ Short Term Memory, LTM =Long Term Memory 
Table 5: Baseline and 1 year follow-up clinical and socio-demographic characteristics comparation among MCI traditional sub-groups and controls

\begin{tabular}{|c|c|c|c|c|c|c|c|c|c|c|c|c|}
\hline & \multicolumn{6}{|c|}{ Baseline } & \multicolumn{6}{|c|}{1 year follow-up } \\
\hline & \multicolumn{2}{|c|}{$\begin{array}{c}\text { CU VS aMCI } \\
\text { Zscore }\end{array}$} & \multicolumn{2}{|c|}{$\begin{array}{c}\text { CU VS maMCI } \\
\text { Zscore }\end{array}$} & \multicolumn{2}{|c|}{$\begin{array}{c}\text { CU VS naMCI } \\
\text { Zscore }\end{array}$} & \multicolumn{2}{|c|}{$\begin{array}{c}\text { CU VS aMCI } \\
\text { Zscore }\end{array}$} & \multicolumn{2}{|c|}{$\begin{array}{c}\text { CU VS maMCI } \\
\text { Zscore }\end{array}$} & \multicolumn{2}{|c|}{$\begin{array}{c}\text { CU VS naMCI } \\
\text { Zscore }\end{array}$} \\
\hline & $\mathbf{t}$ & $\begin{array}{l}\text { Sig. (2- } \\
\text { tailed) }\end{array}$ & $\mathbf{t}$ & $\begin{array}{l}\text { Sig. (2- } \\
\text { tailed) }\end{array}$ & $\mathbf{t}$ & $\begin{array}{l}\text { Sig. (2- } \\
\text { tailed) }\end{array}$ & $\mathbf{t}$ & $\begin{array}{l}\text { Sig. (2- } \\
\text { tailed) }\end{array}$ & $\mathbf{t}$ & $\begin{array}{l}\text { Sig. (2- } \\
\text { tailed) }\end{array}$ & $\mathbf{t}$ & $\begin{array}{l}\text { Sig. (2- } \\
\text { tailed) }\end{array}$ \\
\hline Age & -3.25 & $* *$ & -4.00 & $* * *$ & -.75 & & -3.13 & $* *$ & -4.68 & $* * *$ & -1.03 & \\
\hline Education & 0.09 & & 1.57 & & 2.50 & $*$ & 0.34 & & 2.10 & $*$ & 2.24 & $*$ \\
\hline GDS & -0.54 & & -0.37 & & -.63 & & -0.81 & & -1.76 & & -1.26 & \\
\hline NPI-Q & -1.45 & & -2.31 & $*$ & -0.58 & & -0.11 & & 0.47 & & -1.03 & \\
\hline $\begin{array}{l}\text { Lawton \& } \\
\text { Brody }\end{array}$ & 1.58 & & 2.67 & $*$ & .20 & & 2.53 & $*$ & 4.16 & $* * *$ & 1.00 & \\
\hline CDR & -2.01 & $*$ & -4.23 & $* * *$ & -1.58 & & -3.21 & $* *$ & -6.40 & $* * *$ & -3.09 & $*$ \\
\hline CDR boxes & -1.83 & & -6.98 & $* * *$ & -2.12 & $*$ & -2.32 & $*$ & -5.96 & $* * *$ & -2.28 & $*$ \\
\hline MMSE & 1.25 & & 5.97 & $* * *$ & 2.03 & & 2.09 & $*$ & 5.55 & $* * *$ & 2.31 & $*$ \\
\hline $\begin{array}{l}\text { TAVEC } \\
\text { STM }\end{array}$ & 6.70 & $* * *$ & 10.22 & $* * *$ & 1.08 & & 3.37 & $* *$ & 7.00 & $* * *$ & 0.49 & \\
\hline $\begin{array}{l}\text { TAVEC } \\
\text { LTM }\end{array}$ & 10.36 & $* * *$ & 12.95 & $* * *$ & 1.32 & & 4.37 & $* * *$ & 7.07 & $* * *$ & 0.10 & \\
\hline Rey Copy & 1.79 & & 3.98 & $* * *$ & 1.91 & & 1.93 & & 3.84 & $* * *$ & 2.01 & \\
\hline Rey STM & 3.70 & $* * *$ & 5.88 & $* * *$ & .77 & & 1.70 & & 5.16 & $* * *$ & 0.23 & \\
\hline Rey LTM & 4.31 & $* * *$ & 6.31 & $* * *$ & 1.19 & & 2.38 & $*$ & 5.88 & $* * *$ & 0.94 & \\
\hline Boston & 0.50 & & 3.86 & $* * *$ & 2.37 & $*$ & 0.36 & & 3.91 & $* * *$ & 1.21 & \\
\hline ТМТВА & 0.10 & & -6.21 & $* * *$ & -3.22 & $* *$ & -0.64 & & -4.26 & $* * *$ & -4.70 & $* * *$ \\
\hline $\begin{array}{l}\text { FAS } \\
\text { Phonetics }\end{array}$ & 0.30 & & 3.39 & $* *$ & 4.34 & $* * *$ & 0.55 & & 3.92 & $* * *$ & 3.57 & $* *$ \\
\hline $\begin{array}{l}\text { FAS } \\
\text { Categories }\end{array}$ & 1.27 & & 6.46 & $* * *$ & 2.11 & $*$ & 1.88 & & 6.29 & $* * *$ & 1.92 & \\
\hline Stroop & 1.17 & & 1.29 & & 1.55 & & 0.81 & & 1.23 & & 0.76 & \\
\hline Zoo & 1.41 & & 6.97 & $* * *$ & 2.85 & $*$ & 1.38 & & 3.16 & $* *$ & 0.00 & \\
\hline Similarities & 2.16 & * & 3.11 & $* *$ & 3.39 & $* *$ & 2.00 & & 4.92 & $* * *$ & 2.57 & $*$ \\
\hline $\begin{array}{l}\text { Reverse } \\
\text { Digits }\end{array}$ & -0.27 & & 2.80 & $*$ & 2.37 & $*$ & 0.84 & & 3.27 & $* *$ & 2.84 & $*$ \\
\hline Arithmetics & 0.85 & & 2.80 & $*$ & 2.10 & $*$ & -0.78 & & 1.31 & & 2.21 & $*$ \\
\hline $\begin{array}{l}\text { Letters \& } \\
\text { Numbers }\end{array}$ & 2.48 & $*$ & 4.13 & $* * *$ & 4.26 & $* * *$ & 0.68 & & 4.74 & $* * *$ & 3.91 & $* * *$ \\
\hline
\end{tabular}

${ }^{*} \mathrm{p}<.05, * * \mathrm{p}<, 005,{ }^{* * *} \mathrm{p}<.001 . \mathrm{STM}=$ Short Term Memory, LTM $=$ Long Term Memory 
Table 6: Clinical characteristics, executive tasks' performance, and statistical results from $C U$ and the three MCI clusters

\begin{tabular}{|c|c|c|c|c|c|c|c|}
\hline & $\begin{array}{c}C U \\
N=51 \\
M(S D)\end{array}$ & $\begin{array}{c}\text { Cluster } 1 \\
\mathbf{N}=56 \\
\mathbf{M}(\mathrm{SD})\end{array}$ & $\begin{array}{c}\text { Cluster } 2 \\
\mathrm{~N}=\mathbf{2 8} \\
\mathrm{M}(\mathrm{SD})\end{array}$ & $\begin{array}{c}\text { Cluster } 3 \\
\mathbf{N}=\mathbf{1 0} \\
\mathbf{M}(\mathrm{SD})\end{array}$ & F $(3,140)$ & Sig. & $\begin{array}{c}\text { Partial } \\
\text { ETA2 }\end{array}$ \\
\hline Age & $71.20(4.50)$ & $73.59(6.02)$ & $76.00(5.52)$ & $77.80(5.92)$ & 7.16 & $* * * 0-2,0-3$ & 0.13 \\
\hline Education & $10.14(4.97)$ & $9.46(4.91)$ & $7.61(4.56)$ & $7.10(3.28)$ & 1.78 & & 0.04 \\
\hline GDS & $1.86(2.55)$ & $2.18(2.19)$ & $2.04(1.86)$ & $2.00(1.63)$ & 0.33 & & 0.01 \\
\hline NPI-Q & $0.61(1.15)$ & $1.38(2.01)$ & $0.67(1.04)$ & $1.60(1.58)$ & 2.83 & $*$ & 0.06 \\
\hline $\begin{array}{l}\text { Lawton \& } \\
\text { Brody }\end{array}$ & $7.91(0.59)$ & $7.77(0.71)$ & $7.54(0.96)$ & $6.70(1.06)$ & 5.88 & $* * 0-3,1-3,2-3$ & 0.12 \\
\hline CDR & $0.22(0.27)$ & $0.36(0.23)$ & $0.43(0.23)$ & $0.50(0.00)$ & 4.78 & $* * 0-1,0-2,0-3$ & 0.10 \\
\hline CDR boxes & $6.72(1.28)$ & $7.98(2.30)$ & $9.27(2.68)$ & $11.70(1.34)$ & 14.19 & $* * * 0-1,0-2,0-3,1-3,2-3$ & 0.25 \\
\hline MMSE & $28.94(1.36)$ & $27.82(1.93)$ & $26.43(3.23)$ & $25.30(3.40)$ & 12.40 & $* * *^{0-2,} 0-3,1-2,1-3$ & 0.21 \\
\hline $\begin{array}{l}\text { TAVEC } \\
\text { STM }\end{array}$ & $10.75(2.35)$ & $6.61(3.15)$ & $6.61(4.32)$ & $2.00(2.67)$ & 22.80 & $* * * 0-1,0-2,0-3,1-3,2-3$ & 0.33 \\
\hline $\begin{array}{l}\text { TAVEC } \\
\text { LTM }\end{array}$ & $11.77(2.02)$ & $6.73(3.03)$ & $7.18(3.95)$ & $2.90(2.73)$ & 33.41 & $* * * 0-1,0-2,0-3,1-3,2-3$ & 0.42 \\
\hline Rey Copy & $33.49(3.17)$ & $30.69(6.15)$ & $29.14(7.34)$ & $27.60(9.46)$ & 5.62 & $* *^{0-2,0-3}$ & 0.11 \\
\hline Rey STM & $17.35(6.05)$ & $12.29(7.08)$ & $11.57(7.75)$ & $4.20(3.82)$ & 10.24 & $* * * 0-1,0-2,0-3,1-3,2-3$ & 0.18 \\
\hline Rey LTM & $17.52(6.33)$ & $11.90(6.92)$ & $10.61(7.47)$ & $3.80(2.71)$ & 12.44 & $* * * 0-1,0-2,0-3,1-3,2-3$ & 0.22 \\
\hline Boston & $11.11(2.12)$ & $10.32(2.54)$ & $9.36(2.47)$ & $7.40(2.37)$ & 6.06 & $* * 0-2,0-3,1-3$ & 0.12 \\
\hline ТМТВА & $88.96(62.90)$ & $\begin{array}{c}89.50 \\
(45.33)\end{array}$ & $\begin{array}{l}290.86 \\
(79.34)\end{array}$ & $\begin{array}{c}440.60 \\
(134.60)\end{array}$ & 111.08 & $* * * 0-2,0-3,1-2,1-3,2-3$ & 0.71 \\
\hline $\begin{array}{l}\text { FAS } \\
\text { Phonetics }\end{array}$ & $11.76(3.20)$ & $10.66(3.59)$ & $8.75(3.68)$ & $6.57(3.52)$ & 7.83 & $* * * 0-2,0-3,1-3$ & 0.15 \\
\hline $\begin{array}{l}\text { FAS } \\
\text { Categories }\end{array}$ & $15.16(2.63)$ & $13.20(2.66)$ & $12.94(2.71)$ & $9.48(2.58)$ & 11.05 & $* * * 0-1,0-2,0-3,1-3,2-3$ & 0.20 \\
\hline Stroop & $52.75(6.46)$ & $\begin{array}{c}49.81 \\
(12.01)\end{array}$ & $47.81(18.57)$ & $49.60(8.30)$ & 0.49 & & 0.01 \\
\hline Zoo & $1.93(1.14)$ & $1.04(1.35)$ & $0.64(1.37)$ & $-0.80(0.79)$ & 14.12 & $* * * 0-1,0-2,0-3,1-3,2-3$ & 0.24 \\
\hline Similarities & $17.02(4.69)$ & $14.63(4.74)$ & $13.61(4.52)$ & $11.00(3.43)$ & 5.30 & $* *^{0-2,0-3}$ & 0.11 \\
\hline $\begin{array}{l}\text { Reverse } \\
\text { Digits }\end{array}$ & $5.27(1.59)$ & $5.04(1.78)$ & $4.14(1.48)$ & $3.80(1.03)$ & 4.47 & $*^{0-2}$ & 0.09 \\
\hline Arithmetics & $10.44(3.73)$ & $9.16(3.18)$ & $8.54(3.49)$ & $7.10(1.85)$ & 4.78 & $* * 0-3$ & 0.10 \\
\hline $\begin{array}{l}\text { Letters \& } \\
\text { Numbers }\end{array}$ & $8.20(2.40)$ & $6.82(2.81)$ & $4.89(2.95)$ & $4.00(2.36)$ & 10.09 & $* * *^{0-2,}, 0-3,1-2,1-3$ & 0.18 \\
\hline
\end{tabular}

$* \mathrm{p}<.05, * * \mathrm{p}<.005, * * * \mathrm{p}<.001$. For Bonferroni analysis: $0=\mathrm{CU}, 1=$ Cluster $1,2=$ Cluster 2 and $3=$ Cluster 3. STM = Short Term Memory, LTM = Long Term Memory 
Table 7: Clinical characteristics, executive tasks' performance and statistical results comparation among $C U$ and clusters

\begin{tabular}{|l|cc|cc|cc|}
\hline & \multicolumn{2}{|c|}{ CU VS Cluster 1 Zscore } & \multicolumn{2}{c|}{ CU VS Cluster 2 Zscore } & \multicolumn{2}{c|}{ CU VS Cluster 3 Zscore } \\
& $\mathbf{t}$ & Sig. (2-tailed) & $\mathbf{t}$ & Sig. (2-tailed) & $\mathbf{t}$ & Sig. (2-tailed) \\
\hline Age & -2.34 & $*$ & -4.18 & $* * *$ & -4.03 & $* * *$ \\
Education & 0.70 & & 2.23 & $*$ & 2.43 & $*$ \\
GDS & -0.69 & & -0.32 & & -0.17 & \\
NPI-Q & -2.38 & $*$ & -0.20 & & -2.29 & $*$ \\
Lawton \& Brody & 1.13 & & 1.87 & & 3.50 & $*$ \\
CDR & -2.65 & $*$ & -3.40 & $* *$ & -6.83 & $* * *$ \\
CDR boxes & -3.39 & $* *$ & -4.55 & $* * *$ & -11.00 & $* * *$ \\
MMSE & 3.49 & $* *$ & 3.93 & $* * *$ & 3.33 & $*$ \\
TAVEC STM & 7.67 & $* * *$ & 4.68 & $* * *$ & 10.48 & $* * *$ \\
TAVEC LTM & 9.80 & $* * *$ & 5.72 & $* * *$ & 11.86 & $* * *$ \\
Rey Copy & 2.97 & $* *$ & 2.97 & $*$ & 1.95 & \\
Rey STM & 3.86 & $* * *$ & 3.60 & $* *$ & 8.79 & $* * *$ \\
Rey LTM & 4.24 & $* * *$ & 4.25 & $* * *$ & 10.83 & $* * *$ \\
Boston & 1.67 & & 3.24 & $* *$ & 4.91 & $* * *$ \\
TMTBA & -0.05 & & -12.12 & $* * *$ & -8.07 & $* * *$ \\
FAS Phonetics & 1.62 & & 3.71 & $* * *$ & 4.58 & $* * *$ \\
FAS Categories & 3.72 & $* * *$ & 3.48 & $* *$ & 6.22 & $* * *$ \\
Stroop & 1.57 & & 1.36 & & 1.32 & \\
Zoo & 3.63 & $* * *$ & 4.36 & $* * *$ & 7.21 & $* * *$ \\
Similarities & 2.56 & $*$ & 3.08 & $* *$ & 3.83 & $* * *$ \\
Reverse Digits & 0.68 & & 3.02 & $* *$ & 2.78 & $*$ \\
Arithmetics & 1.86 & & 2.18 & $*$ & 2.74 & $*$ \\
Letters \& Numbers & 2.62 & $*$ & 5.26 & $* * *$ & 5.02 & $* * *$ \\
\hline
\end{tabular}

${ }^{*} \mathrm{p}<.05,{ }^{*} \mathrm{p}<, 005,{ }^{*} * \mathrm{p}<.001 . \mathrm{STM}=$ Short Term Memory, LTM =Long Term Memory 
Table 8: Distribution of participants that progress to dementia in ACS a year later

\begin{tabular}{lcccccc} 
& \multicolumn{3}{c}{ MCI } & \multicolumn{3}{c}{ Clusters } \\
\cline { 2 - 7 } & $\mathbf{a}$ & ma & na & $\mathbf{1}$ & $\mathbf{2}$ & $\mathbf{3}$ \\
\hline $\mathbf{N}$ & 22 & 48 & 15 & 57 & 28 & 10 \\
Conversion & 0 & 10 & 0 & 0 & 0 & 10 \\
$\mathbf{\%}$ & 0 & $\mathbf{2 0 . 8 3 \%}$ & 0 & 0 & 0 & $\mathbf{1 0 0 \%}$ \\
\hline
\end{tabular}


Table 9: Baseline assessment of executive functions of converter and stable MCI

\begin{tabular}{|c|c|c|c|c|c|}
\hline & $\begin{array}{c}\text { Converter } \\
\mathbf{N}=10 \\
\mathbf{M} \text { (SD) }\end{array}$ & $\begin{array}{l}\text { Stable } \\
\mathbf{N}=\mathbf{6 2} \\
M \text { (SD) }\end{array}$ & $\mathbf{t}$ & Sig. & $\begin{array}{l}\text { Effect size } \\
\text { (Cohen-d) }\end{array}$ \\
\hline Age & $77.80(5.92)$ & $74.47(6.30)$ & -1.561 & & 0.545 \\
\hline Education & $7.10(3.28)$ & $8.62(5.11)$ & .905 & & -0.354 \\
\hline GDS & $2.00(1.63)$ & $2.07(1.84)$ & .108 & & -0.04 \\
\hline NPI-Q & $1.60(1.58)$ & $1.08(1.70)$ & -0.90 & & 0.32 \\
\hline Lawton \& Brody & $6.70(1.06)$ & $7.72(0.72)$ & 2.926 & $*$ & -1.126 \\
\hline CDR & $0.50(0.00)$ & $0.40(0.20)$ & -3.848 & $* * *$ & 0.707 \\
\hline CDR boxes & $11.70(1.34)$ & $8.54(2.50)$ & -5.870 & $* * *$ & 1.576 \\
\hline MMSE & $25.30(3.40)$ & $27.33(2.50)$ & 2.256 & $*$ & -0.68 \\
\hline TAVEC STM & $2.00(2.67)$ & $6.83(3.43)$ & 4.237 & $* * *$ & -1.571 \\
\hline TAVEC LTM & $2.90(2.73)$ & $7.37(3.18)$ & 4.182 & $* * *$ & -1.508 \\
\hline Rey Copy & $27.60(9.46)$ & 30.68 (5.95) & 1.384 & & -0.39 \\
\hline Rey STM & $4.20(3.82)$ & $12.21(7.19)$ & 3.426 & $* *$ & -1.391 \\
\hline Rey LTM & $3.80(2.71)$ & $11.76(6.78)$ & 6.498 & $* * *$ & -1.542 \\
\hline Boston & $7.40(2.37)$ & $10.03(2.44)$ & 3.170 & $* *$ & -1.093 \\
\hline TMTBA & $440.60(134.60)$ & $159.50(116.11)$ & -6.932 & $* * *$ & 2.236 \\
\hline FAS Phonetics & $6.57(3.52)$ & $9.94(3.71)$ & 2.676 & $*$ & -0.932 \\
\hline FAS Categories & $9.48(2.58)$ & $13.06(2.60)$ & 4.042 & $* * *$ & -1.382 \\
\hline Stroop & $49.60(8.30)$ & $49.44(13.42)$ & -.036 & & 0.014 \\
\hline Zoo & $(-) 0.80(0.79)$ & $0.82(1.36)$ & 3.646 & $* *$ & -1.457 \\
\hline Similarities & $11.00(3.43)$ & $14.52(4.92)$ & 2.167 & $*$ & -0.83 \\
\hline Reverse Digits & $3.80(1.03)$ & $4.67(1.61)$ & 1.639 & & -0.644 \\
\hline Arithmetics & $7.10(1.85)$ & $9.12(3.44)$ & 1.803 & & -0.731 \\
\hline Letters \& Numbers & $4.00(2.36)$ & $6.27(3.04)$ & 2.246 & $*$ & -0.834 \\
\hline
\end{tabular}

${ }^{*} \mathrm{p}<.05,{ }^{* *} \mathrm{p}<.005 * * * \mathrm{p}<.001 . \mathrm{STM}=$ Short Term Memory, LTM = Long Term Memory 
Tabla 10: Simple (top-row) and stepwise (bottom row) linear regression models including executive function components.

\begin{tabular}{lccc} 
& F & Sig. & R2 \\
\hline TMTB-A & 48.052 & 0.000 & .414 \\
TMTB-A + Fluency Semantic Categories & 27.489 & 0.000 & .451 \\
\hline
\end{tabular}


Table 11: Simple (top-row) and stepwise (bottom row) linear regression models including classical (memory-based) MCI and dysexecutive MCI.

\begin{tabular}{lccc} 
& F & Sig. & R2 \\
\hline Classical MCI & 0.082 & 0.776 & 0.001 \\
Dysexecutive MCI & 41.917 & 0.000 & 0.381 \\
\hline Classical MCI + MMSE & 5.090 & 0.955 & 0,070 \\
Dysexecutive MCI + MMSE & 116.251 & 0.000 & 0.631 \\
\hline
\end{tabular}


Table 12: Stepwise (bottom row) linear regression model including dysexecutive MCI classification and category fluency test.

\begin{tabular}{lccc}
\cline { 2 - 4 } & F & Sig. & R2 \\
\hline Dysexecutive MCI & 116.251 & 0.000 & 0.631 \\
Dysexecutive MCI + Category Fluency & 62.934 & 0.000 & 0.653 \\
\hline
\end{tabular}




\section{Figures}

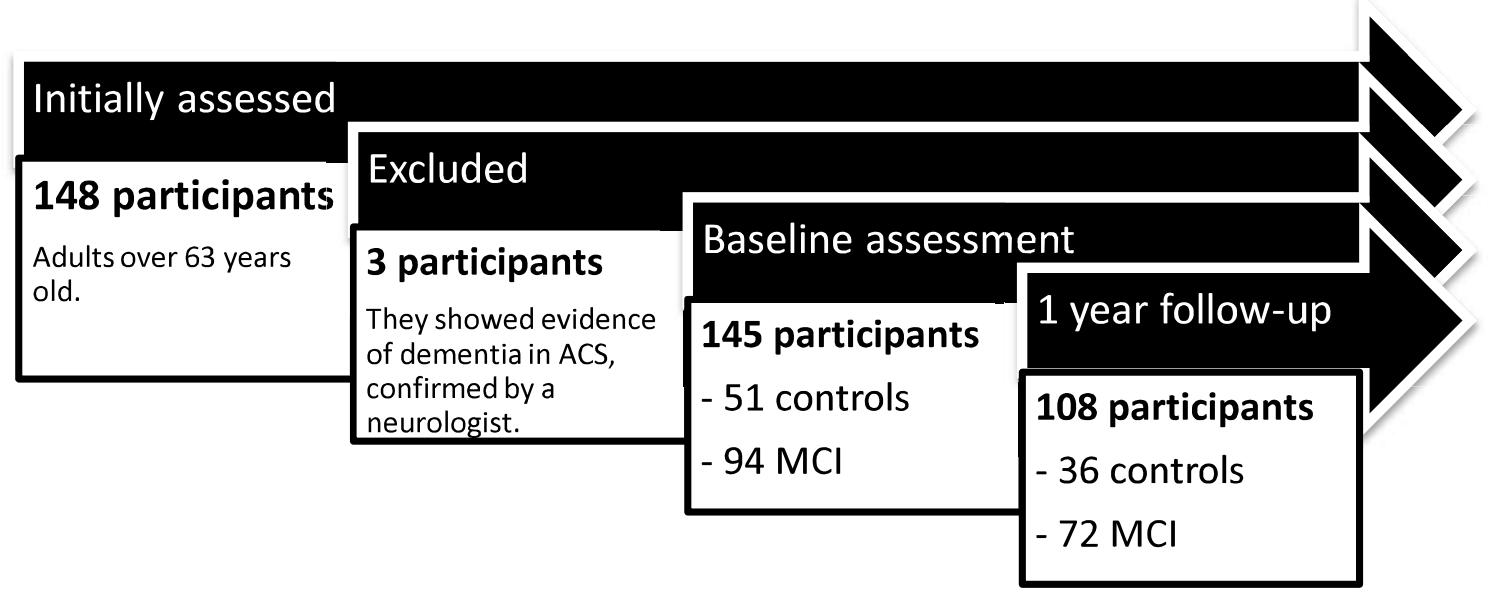

Figure. 1: Study Sample Flowchart 


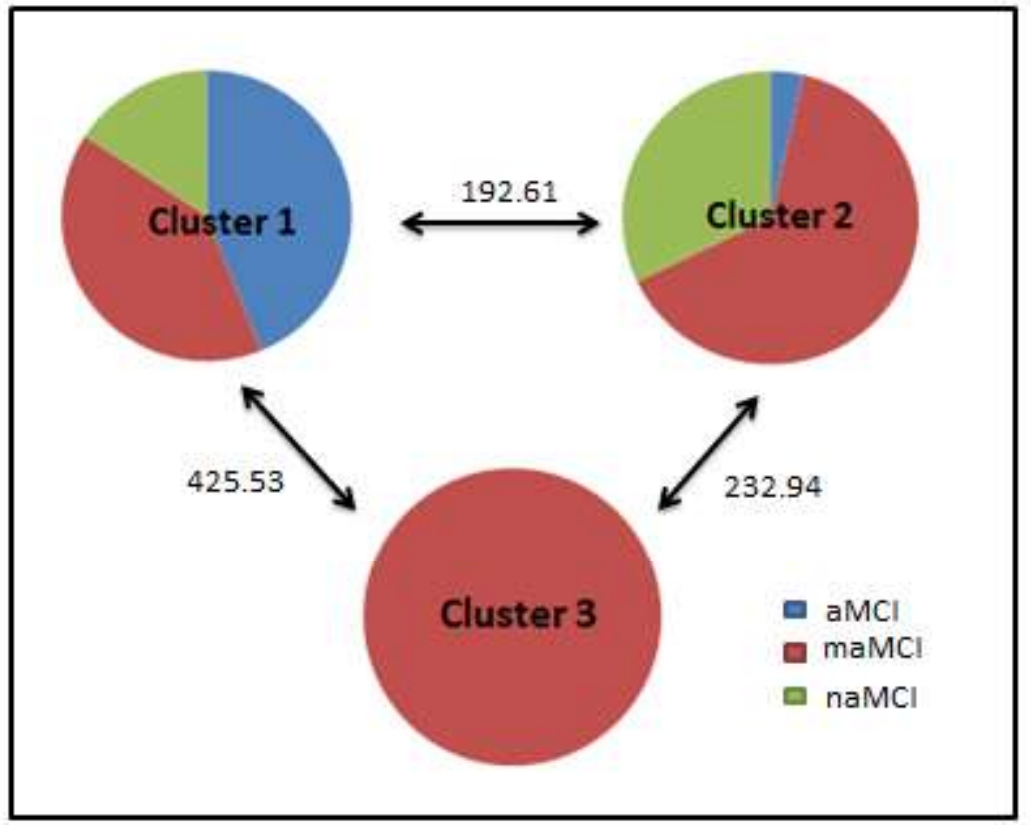

Figure 2: Classical MCI groups' distribution in our clusters and distance between them. 